\title{
Título da página electrónica: Mission de Recherche Droit et Justice
}

Endereço: http://www.gip-recherche-justice.fr/

João Paulo Dias

\section{OpenEdition}

\section{Journals}

Edição electrónica

URL: http://journals.openedition.org/rccs/1196

DOI: $10.4000 /$ rccs. 1196

ISSN: 2182-7435

\section{Editora}

Centro de Estudos Sociais da Universidade de Coimbra

\section{Edição impressa}

Data de publição: 1 maio 2003

Paginação: 193-194

ISSN: 0254-1106

\section{Refêrencia eletrónica}

João Paulo Dias, «Título da página electrónica: Mission de Recherche Droit et Justice », Revista Crítica de Ciências Sociais [Online], 65 | 2003, posto online no dia 01 outubro 2012, consultado o 21 setembro 2020. URL : http://journals.openedition.org/rccs/1196; DOI : https://doi.org/10.4000/rccs.1196 


\section{Espaço Virtual}

\section{Título da página electrónica: La Documentation Française Endereço: http://www.ladocumentationfrancaise.fr/}

Esta página permite aceder a uma variedade enorme de relatórios públicos, sobre os mais diversos temas, na maior parte das vezes encomendados pelos diferentes órgãos governamentais a centros de investigação especializados e a universidades em geral. A consulta da lista de publicações, de discursos públicos, de revistas, de documentação fotográfica, de documentários e de um conjunto de informações relacionadas com assuntos actuais demonstra a colaboração, possível e importante, entre as diversas entidades governamentais e os centros de produção de conhecimento existentes na sociedade, neste caso a francesa. Além disso, há que realçar diversos aspectos: a completa divulgação destas informações, de acesso livre; a tomada de decisões devidamente fundamentada em relatórios; a avaliação contínua das medidas implementadas; a divulgação das actividades das entidades públicas; a interacção entre a informação nacional e a realidade internacional; e o estímulo dado à participação dos cidadãos, providenciando-lhes a informação necessária.

A diversidade de temas abordados, a profundidade das análises, a excelência dos centros de investigação envolvidos e a riqueza dos estudos comparativos permite, em muitas matérias, construir bons momentos de reflexão e dotar as entidades públicas, e o público em geral, com instrumentos de intervenção e de decisão política muito importantes.

De entre os variadíssimos relatórios disponíveis, vamos apenas destacar os incluídos no item "Questões jurídicas", deixando de fora os restantes 21 itens em que se divide a zona relativa aos relatórios públi$\cos$ (agricultura, cultura, defesa, trabalho, etc., são apenas alguns dos outros temas consultáveis). Neste sector encontramos, em Abril de 2003, cerca de 160 relatórios produzidos nos últimos seis anos. Entre os temas abordados, enunciamos a título de exemplo, e sem pretender hierarquizar ou destacar algum, os seguintes relatórios: Mission d'étude des législations de la nationalité et de l'immigration (coord. Patrick Veil, 1997); Enquête: les Français et la justice: jugements et attentes (Mission recherche droit et justice, 1997); L'évolution du droit de l'espace en France (coord. Alain Costes, 2003); Rapport de la Commission d'enquête sur la délinquance des mineurs (coord. Jean-Claude Carle e Jean-Pierre Shosteck, 2002); Les Lois de la bioéthique: cinq ans après (coord. Jean-François Thery, Frédéric Salat-Baroux e Christine Le Bihan-Graf, 1999); L'influence internationale $d u$ droit français (coord. Olivier Dutheillet de Lamothe e Marie-Aimée Latournerie, 2001); La réforme de l'accès au droit et à la justice (coord. Paul Bouchet, Dominique Charvet e Bertrand Fragonard, 2001); e Qualité de la justice et évaluation des tribunaux de grande instance (coord. Hubert Dalle, 2001).

Encontramos ainda relatórios de actividades de órgãos como o Conselho Superior de Magistratura, o Tribunal de Cassação, a Administração Penitenciária ou o próprio Ministério da Justiça, entre vários relativos ao funcionamento de Missões ou Comissões para assuntos específicos. De referir apenas a diminuição verificada nos últimos dois anos na publicação de relató- 
rios neste sector. As razões desta diminuição são por nós desconhecidas, esperando apenas que seja um momento transitório. Esta página presta, sem dúvida, um bom serviço público, não só aos cidadãos em geral, mas também aos investigadores das mais diversas áreas, através da divulgação de informação muito útil. $\mathrm{O}$ acesso à informação é fácil, embora a sua estrutura não seja das mais simples. A diversidade de informação e a sua distribuição são relativamente articuladas, ainda que por vezes gerem alguma confusão devido à transdisciplinaridade de muitos documentos ou relatórios, que aparecem repetidos em zonas distintas. A sua actualidade, contudo, confere uma importância acrescida a este site.

\section{Título da página electrónica: Development Gateway Endereço: www.developmentgateway.org/}

Esta página é desenvolvida pela Development Gateway Foundation, que se intitula uma organização sem fins lucrativos e tem como missão a redução da pobreza e o apoio ao desenvolvimento sustentável baseado na disseminação de informação e de tecnologias da comunicação. A lista de entidades que participam neste projecto é muito diversificada e apresenta-se em níveis muito distintos. Desde instituições académicas e de investigação (Biblioteca Alexandrina, Pontifícia Universidade Católica do Peru, etc.) a organizações não governamentais (Soros Foundation, Microcredit Summit Campaign, etc.), passando por organizações internacionais (OMC, ONU, OIT, etc.) ou empresas (IBM, Microsoft, etc.), de diferentes pontos do mundo. Entre as instituições financiadoras temos o Banco Mundial, o Fundo Monetário Internacional, a United States Agency for International Development ou o Banco Europeu para o Investimento, entre outras instituições financeiras de importância mundial ou, pelo menos, regional.

A página de entrada deste site permite efectuar uma opção entre quatro grandes tópicos disponíveis: intercâmbio de ideias e conhecimento; desenvolvimento de projectos; oportunidade de realizar negócios; e acesso a portais referentes a países. No entanto, a procura por tópicos disponibiliza um leque de 32 opções bastante variadas, que vão desde a glocalização, à crise argentina, aos negócios ambientais, aos direitos indígenas, à segurança alimentar, entre outros. Acresce a esta possibilidade, a selecção destes tópicos em função do país que se deseja pesquisar.

A escolha do item "Reforma legal e judicial" (judicial and legal reform) permite-nos entrar numa área onde existe bastante informação relacionada com os sistemas judiciais e projectos de reforma em curso em muitos países do mundo, com especial incidência nos país em vias de desenvolvimento. As palavras-chave para a navegação são: instituições jurídicas e judiciárias, direito e justiça na redução da pobreza, estatísticas jurídicas e judiciais, reforma judicial, reforma jurídica e acesso à justiça.

Entre a informação disponibilizada, podemos discriminar a seguinte: dados e estatísticas, documentos e relatórios, eventos e fóruns de discussão, organizações e redes, programas e projectos e publicações e multimédia. Os relatórios disponíveis, por exemplo, são muito diversificados, tal como demonstram os seguintes exemplos, seleccionados aleatoriamente: International Commission of Jurists (ICJ) released its final report on Afghanistan's legal system 
(2003); How legal reform can belp developing nations (2003); What kind of judicial power does China need? (2003); Legal and Judicial Reforms Project - Sri Lanka (2003); Legal and Judicial Co-operation ProgrammeEurope and China (2003); Test of Judicial Reform in Indonesia (2002). Os exemplos demonstram a grande incidência das intervenções das organizações financeiras internacionais em países em transição para sistemas democráticos ou em vias de desenvolvimento, permitindo retirar um conjunto de informação para todos os investigadores, decisores políticos e/ou juristas que trabalhem nas áreas do direito e da justiça e da cooperação internacional. Este site inclui ainda um local onde se podem consultar oportunidades de emprego relativamente a projectos de desenvolvimento nos mais variados países onde as agências internacionais intervêm.
A página pode ser consultada em três línguas: espanhol, inglês e francês. A informação disponível é relativamente acessível e fácil de encontrar. A navegação é, por vezes, algo lenta e a articulação entre a variadíssima informação não é a mais clara e rápida. No entanto, a página disponibiliza muitos conteúdos que permitem compreender e aceder às actividades desenvolvidas pelas instituições internacionais que actuam na área do direito e da justiça, através da promoção de projectos de desenvolvimento nacionais e locais. Este acesso permite, ainda, analisar as alterações nas políticas internacionais e o foco atribuído, com cada vez maior ênfase, às reformas na área do direito e da justiça como elemento fundamental para o desenvolvimento do mercado em associação com os sistemas democráticos.

\section{Título da página electrónica: Mission de Recherche Droit et Justice Endereço: http://www.gip-recherche-justice.fr/}

A Mission de Recherche Droit et Justice foi criada, em 1994, numa iniciativa conjunta entre o Ministério da Justiça francês e o Centre Nationale de Recherches Scientifiques. Esta associação permite a integração, numa estrutura comum, de meios humanos, intelectuais e materiais, públicos e privados, considerados necessários para o desenvolvimento de actividades científicas de investigação. Entre os seus membros fundadores com poderes deliberativos no Conselho de Administração, encontramos também a École Nationale de Magistrature, o Conseil National des Barreaux e o Conseil Supérieur du Notariat. Estão ainda associados a esta estrutura o Institut des Hautes Études sur la Justice e a Association Française pour l'Histoire de la Justice. O objectivo geral desta estrutura de investigação visou a constituição de um potencial de investigação sobre as questões do direito e da justiça, no âmbito dos mais variados campos disciplinares. Assim, segundo o descrito no site, ela tem como objectivos; a definição, a avaliação e a coordenação dos programas de investigação sobre a justiça; a identificação e a manutenção de equipas multidisciplinares susceptíveis de ter um papel importante neste campo; a coordenação das actividades de organismos que trabalhem sobre estes temas; o estímulo ao intercâmbio de profissionais, de universitário e de investigadores; a manutenção de informação actualizada e a valorização da investigação, através da cooperação com escolas e organismos relacionados com a formação profissional na área da justiça; e o desenvolvimento da cooperação internacional. 
As actividades desenvolvidas originaram a criação de três colecções de publicações. Uma, no âmbito das Presses Universitaires de France, designada "Droit et Justice". Outra, publicada na Documentation Française, com o título de "Perspectives sur la Justice”. A terceira, sem fins comerciais, tem por título "Arrêt sur Recherches”, e é gerida pela própria Missão.

A quantidade e diversidade de informação disponibilizada é bastante grande, alicerçada em vários anos de investigação. O portal de entrada encontra-se dividido em actualidades, programa científico, investigações, publicações, dossiers temáticos, apresentação de projectos e fontes, para além da apresentação da Missão, dos seus membros e dos objectivos que perseguem. Entre os relatórios e publicações consultáveis, vou destacar apenas alguns que demonstram a variedade e qualidade do seu trabalho: Conflit familial, déplacements d'enfants et coopération judiciaire internationale en Europe (coord. Hugues Fulchiron, 2003); Une justice de proximité: la justice de paix (1790-1958) (coord. Jacques-
-Guy Petit, 2002); L'aide aux demandeurs d'asile: la part du mouvement associatif dans l'accès au droit d'asile (coord. Spyros Franguidakis, 2002); Accès à la justice disciplinaire (coord. Joël Moret-Bailly, Karine Laroche, Nathalie Merley, Françoise Pernet-Richard, 2002); e La qualité de la justice. Une analyse économique exploratoire (coord. Christian Barrére, 2002). Os relatórios são elaborados por equipas de investigação provenientes das mais diversas universidades e centros de investigação.

A navegação é bastante fácil e simples. A informação está disponível para consulta e, num grande número de casos, para impressão. É um site que se recomenda a todos os decisores políticos, juristas e investigadores nas áreas da justiça e do direito. A informação contida revela também uma transparência e importância atribuída à divulgação de informação produzida, prestando um serviço público de grande utilidade.

João Paulo Dias 